\title{
Inferring dynamics from the wavenumber spectra of an eddying global ocean model with embedded tides
}

\author{
James G. Richman, ${ }^{1}$ Brian K. Arbic, ${ }^{2}$ Jay F. Shriver, ${ }^{1}$ E. Joseph Metzger, ${ }^{1}$ \\ and Alan J. Wallcraft ${ }^{1}$ \\ Received 16 July 2012; revised 18 October 2012; accepted 22 October 2012; published 12 December 2012.
}

[1] The slopes of the wavenumber spectra of sea surface height ( $\mathrm{SSH}$ ) and kinetic energy

(KE) have been used to infer "interior" or surface quasi-geostrophic (QG or SQG)

dynamics of the ocean. However, inspection of spectral slopes for altimeter SSH in the mesoscale band of 70 to $250 \mathrm{~km}$ shows much flatter slopes than the QG or SQG predictions over most of the ocean. Comparison of altimeter wavenumber spectra with spectra from an eddy resolving global ocean circulation model (the HYbrid Coordinate Ocean Model, HYCOM, at $1 / 12.5^{\circ}$ equatorial resolution), which has embedded tides, suggests that the flatter slopes of the altimeter SSH may arise from three possible sources: (1) presence of strong internal tides, (2) shift of the inertial sub-range to smaller scales and (3) altimeter noise. Artificially adding noise to the model tends to flatten the spectra for low KE regions. Near internal tide generating regions, spectral slopes in the presence of internal waves are much flatter than QG or SQG predictions. Separating the variability into high and low frequency (around periods of 2 days), then a different pattern emerges with a flat high-frequency wavenumber spectrum and a steeper low-frequency wavenumber spectrum. For low mesoscale KE, the inertial sub-range, defined by the nearly flat enstrophy band, moves to smaller scales and the mesoscale band of 70 to $250 \mathrm{~km}$ no longer represents the inertial sub-range. The model wavenumber spectra are consistent with QG and SQG theory when internal waves and inertial sub-range shifts are taken into consideration.

Citation: Richman, J. G., B. K. Arbic, J. F. Shriver, E. J. Metzger, and A. J. Wallcraft (2012), Inferring dynamics from the wavenumber spectra of an eddying global ocean model with embedded tides, J. Geophys. Res., 117, C12012, doi:10.1029/2012JC008364.

\section{Introduction}

[2] The slope of the wavenumber spectrum of sea surface height ( $\mathrm{SSH}$ ) and kinetic energy (KE) over the mesoscale band has been used to infer the dynamics of geostrophic oceanic flows. For instance, it has been argued, for quasigeostrophic (QG) dynamics dominated by "interior" potential vorticity, that the wavenumber $(\mathrm{k})$ spectrum of kinetic energy varies as $\mathrm{k}^{-3}$ [Stammer, 1997; Le Traon et al., 2008; Sasaki and Klein, 2012]. For geostrophically balanced flows, a steeper SSH spectrum varying as $\mathrm{k}^{-5}$ will occur. Near the surface, the dynamics of quasi-geostrophic flow with uniform potential vorticity in the interior (Surface QuasiGeostrophy, SQG) yields a kinetic energy wavenumber spectrum which is flatter varying as $\mathrm{k}^{-5 / 3}$, while the $\mathrm{SSH}$

\footnotetext{
${ }^{1}$ Oceanography Division, Naval Research Laboratory, Stennis Space Center, Mississippi, USA.

${ }^{2}$ Department of Earth and Environmental Sciences, University of Michigan, Ann Arbor, Michigan, USA.

Corresponding author: J. G. Richman, Oceanography Division, Naval Research Laboratory, Code 7323, Stennis Space Center, MS 39529, USA. (james.richman@nrlssc.navy.mil)

This paper is not subject to U.S. copyright.

Published in 2012 by the American Geophysical Union.
}

wavenumber spectrum varies as $\mathrm{k}^{-11 / 3}$ [e.g., Le Traon et al., 2008; Sasaki and Klein, 2012].

[3] Satellite altimeter data [Fu and Cazenave, 2001] with its global coverage provide a unique opportunity to estimate SSH wavenumber spectra. However, altimeter observations present a number of interesting difficulties. For instance, near the ocean surface, strong ageostrophic motions due to wind-forcing, tides and internal waves exist and can change the spectrum of SSH and KE. The 10-day sampling period of the TOPEX/Poseidon and Jason altimeters implies that highfrequency variability will be aliased into longer periods, thus mixing high- and low-frequency signals in the altimeter data. For stationary high frequency variability with known periods, such as tides, it is possible to recover the aliased variability. However, contamination of tidal signals by mesoscale motions makes perfect recovery of the tides impossible [Tierney et al., 1998; Carrère et al., 2004] and thus leaves some tidal energy even in so-called "de-tided" altimeter data. If the geostrophic approximation is made, the geostrophic velocities can be estimated from the SSH. However, ageostrophic velocities cannot be estimated from altimeter data.

[4] To investigate the impact of the ageostrophic motions on the wavenumber spectra of SSH and KE, we calculate wavenumber spectra using the output of an eddy resolving global ocean circulation model, the HYbrid Coordinate 
Ocean Model (HYCOM) [Chassignet et al., 2007; Metzger et al., 2010] with $1 / 12.5^{\circ}$ (approximately $9 \mathrm{~km}$ ) equatorial resolution, which is forced by the astronomical tidal potential of the Sun and Moon, as well as by atmospheric wind and buoyancy fields. In the concurrent wind- and tidallyforced HYCOM simulations [Arbic et al., 2010, 2012], barotropic tides are predicted within the eddy resolving ocean general circulation model. The barotropic tides in turn interact with bottom topography to generate low vertical mode internal waves which propagate for thousands of kilometers from the generating region [Ray and Mitchum, 1996, 1997]. The barotropic and internal tides in the model compare well with altimetric estimates [Shriver et al., 2012].

[5] In this paper we estimate wavenumber spectra of the HYCOM SSH and KE fields. The impact of high-frequency motions on wavenumber spectra is demonstrated by taking advantage of the frequent (one hour) sampling of HYCOM to separate low- from high-frequency motions, which is not possible in the aliased altimeter data. With the model, we can examine kinetic energy spectra using both total and geostrophic velocity, which cannot be done with the altimeter data. We compare the spectral slopes in our HYCOM simulations with both predictions from the theory of SQG and QG turbulence and with estimates made from alongtrack altimeter data by $X u$ and $F u[2011,2012] . X u$ and $F u$ [2011, 2012] estimate the spectral slopes over a fixed "mesoscale" wavelength band $(70-250 \mathrm{~km})$ and find the SSH spectral slopes to be much flatter than the predictions of the SQG or QG theory for much of the world ocean. Our model has much steeper slopes for the low-frequency $\mathrm{SSH}$ and KE. Three possible reasons for the differences between our model spectra and $X u$ and $F u$ [2011, 2012] are presented: (1) low-mode internal waves with wavelengths in the mesoscale band, (2) lack of an inertial sub-range in the mesoscale band and (3) altimeter noise.

\section{The Model}

[6] To concurrently simulate ocean tides and circulation, astronomical tidal forcing [Cartwright, 1999], self-attraction and loading [Hendershott, 1972], and parameterized topographic internal wave drag [Garner, 2005] have been added to global HYCOM, as in Arbic et al. [2010, 2012]. The astronomical tidal forcing for the four largest semidiurnal constituents $\left(\mathrm{M}_{2}, \mathrm{~S}_{2}, \mathrm{~N}_{2}\right.$, and $\left.\mathrm{K}_{2}\right)$ and the four largest diurnal constituents $\left(\mathrm{K}_{1}, \mathrm{O}_{1}, \mathrm{P}_{1}\right.$, and $\left.\mathrm{Q}_{1}\right)$ is adjusted for the deformation of the solid Earth body tides [Hendershott, 1972]. The self-attraction and loading term arises from alterations in the gravitational equipotential due to the self-attraction of the load-deformed solid Earth and the self-attraction of the ocean tides themselves [Hendershott, 1972]. The selfattraction and loading can be calculated iteratively from the model tidal elevations, but, for computational simplicity, a scalar approximation [Ray, 1998] currently is used in our model. The topographic internal wave drag term accounts for damping and energy loss due to the generation and subsequent breaking of internal tides generated by barotropic tidal flow over rough topography. Topographic internal wave drag has been introduced into many global barotropic tide models, [e.g., Jayne and St. Laurent, 2001; Egbert et al., 2004; Arbic et al., 2004], motivated by inferences from satellite-altimetry constrained tide models of enhanced open-ocean tidal dissipation in regions of rough topography [Egbert and Ray, 2000] and by in situ measurements of enhanced energy dissipation and mixing in such regions, [e.g., Polzin et al., 1997]. The parameterized wave drag scheme in HYCOM is based on the atmospheric mountain drag scheme of Garner [2005], as implemented by Arbic et al. [2004]. As discussed in Arbic et al. [2010], a parameterized wave drag is still used in the global baroclinic simulations, because the model generates only the low-mode internal tides, not the higher-mode internal waves which break and dissipate. The concurrent tide and circulation model is still under development with frequent updates and improvements. As a result, the simulations of this study are not identical to those discussed in Arbic et al. [2010]. However, the differences between the two sets of simulations are small and of no consequence for the results presented here.

[7] The model for concurrent tides and circulation has 32 layers in the vertical direction and a nominal equatorial horizontal resolution of $1 / 12.5^{\circ}$ [Metzger et al., 2010]. The simulation spans 2003-2010 using 3-hourly Fleet Numerical Meteorology and Oceanography Center Navy Operational Global Atmospheric Prediction System [Rosmond et al., 2002] atmospheric forcing with wind speeds scaled to be consistent with QuikSCAT observations [Kara et al., 2009]. The model generates a realistic circulation; although comparison to surface drifters and deep current meters shows the model is deficient in eddy kinetic energy (EKE), being only $79 \%$ and $80 \%$ of the observations at the surface and abyssal ocean [Thoppil et al., 2011]. Snapshots of the SSH and surface velocity are saved once per hour for this six year period and hourly snapshots of the entire three-dimensional fields are archived for two 30 day periods (Sept. 2004 and March 2009). For this study we use the surface data for the calendar year 2006.

\section{Validation of Barotropic and Internal Tides}

[8] Tidal sea surface elevations are dominated by the barotropic tide. The barotropic tide in HYCOM captures $93.2 \%$ of the sea surface elevation variance of the eight largest tidal constituents in a standard set of 102 pelagic tide gauges [Shum et al., 1997]. The barotropic tide in HYCOM can be compared to altimetry-constrained barotropic shallow water tide models. The $\mathrm{M}_{2}$ surface elevation amplitudes for HYCOM and a barotropic shallow water model which assimilates altimetric tidal heights (TPXO7.2, updated from Egbert et al. [1994]) are shown in Figures 1a and 1b respectively. Comparison of the amplitudes and phases in Figure 1 demonstrates that the barotropic tide in HYCOM is quite realistic. When the HYCOM tides are remapped to the TPXO grid, the RMS difference between the two models is $7.5 \mathrm{~cm}$, which is less than the $7.8 \mathrm{~cm}$ RMS difference between HYCOM and the 102 pelagic gauges. The largest difference between the HYCOM and TPXO tidal models occurs in the Southern Ocean and North Atlantic. In the Southern Ocean, the bathymetry in the two models is very different with HYCOM placing a solid boundary at the floating ice shelves and TPXO replacing the floating ice shelves with reduced depth ocean. Much more detailed comparisons of the barotropic tides in HYCOM and TPXO are discussed in Shriver et al. [2012]. 
(a) HYCOM

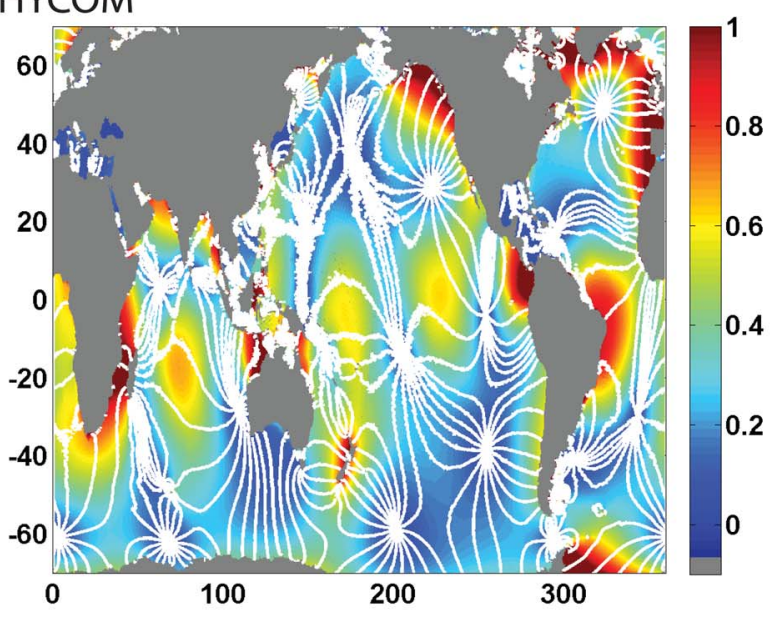

(b) TPX07.2

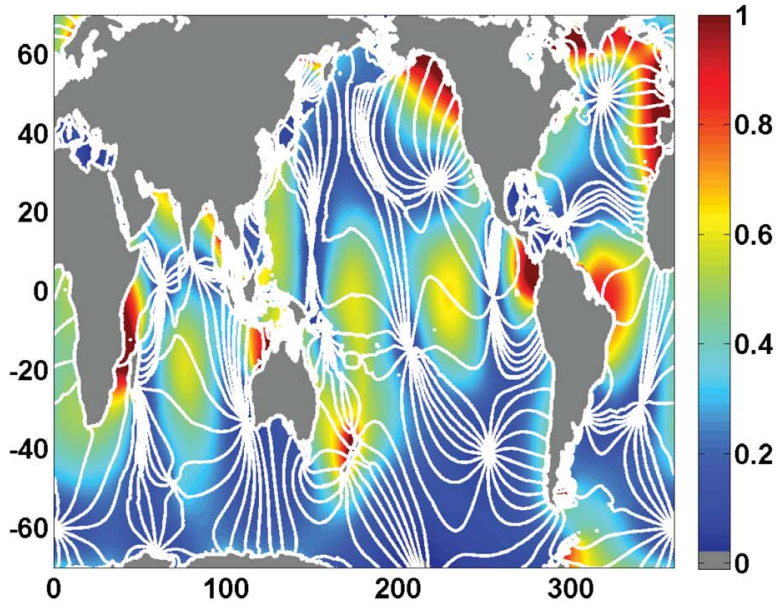

Figure 1. $\mathrm{M}_{2}$ sea surface elevation amplitudes $(\mathrm{m})$ and phase for (a) HYCOM and (b) TPXO7.2 [Egbert et al., 1994], a highly accurate altimetry-constrained model of the barotropic tides. White lines indicate phase, drawn $20^{\circ}$ apart.

[9] Barotropic tidal currents interact with the bottom topography in the presence of stratification to generate internal tides which propagate for thousands of kilometers away from the source regions. Although the largest internal tide displacements occur at depth, internal tide signals at the sea surface are large enough to be detected by satellite altimeters [Ray and Mitchum, 1996, 1997]. For the altimeter, the tidal amplitudes are recovered from the aliased track data using a response method. In Figure 2 we display the results of a 50-400 km band-pass of $\mathrm{M}_{2}$ amplitudes for along-track altimeter data with a correction for mesoscale contamination [Ray and Byrne, 2010] and for HYCOM interpolated along the altimeter tracks. Band-passing removes both small-scale noise present in the altimeter data, and large-scale barotropic tides present in both the altimeter data and HYCOM. Hot spots of semidiurnal internal tide generation are seen around Hawai'i, the Philippines, the tropical south and southwest Pacific, and Madagascar. As Figure 2 visually demonstrates, the strength of the internal tide in HYCOM and altimeter data is quite comparable near the hot spots. To be more quantitative, the RMS amplitudes of the semidiurnal internal tides averaged in boxes around these hot spots agree within 9-26\% [Shriver et al., 2012]. In regions of strong mesoscale eddies, leakage from the eddies, which have similar length scales and time scales near the alias frequency of the tides, makes an accurate estimate of the internal tidal amplitudes from altimeter data more difficult (see, for instance, the large amplitudes of the tides in the Gulf Stream in Figure 2a). For the sake of brevity, similar maps for the leading diurnal tides, $\mathrm{K}_{1}$ and $\mathrm{O}_{1}$, are not shown here, but can be found in Shriver et al. [2012]. We note here that a similar picture for the diurnal internal tides emerges with good comparison at the hot spots. For diurnal tides mesoscale leakage in the altimeter estimates is especially apparent poleward of $30^{\circ}$, where diurnal internal waves cannot propagate.

\section{Wavenumber Spectra}

[10] Wavenumber spectra of SSH and KE can be estimated from the model. For the SSH and velocity, data from an hourly snapshot of the model are sampled in $10^{\circ}$ by $10^{\circ}$ boxes. For each box, the mean of the SSH and velocity components is removed and a $10 \%$ cosine taper window applied in both the zonal and meridional directions. A twodimensional periodogram is calculated for the snapshot. The periodograms are averaged over all the snapshots for 2006. The resultant spectrum is converted from Cartesian wavenumbers to polar wavenumbers and averaged over direction to produce the scalar wavenumber spectrum. For the kinetic energy, the individual velocity component spectra are estimated and summed, with division by two, to determine the kinetic energy spectra. Spectral slopes for a fixed mesoscale wavelength band of 70 to $250 \mathrm{~km}$ will be estimated by least squares from the $\mathrm{SSH}$ and $\mathrm{KE}$ wavenumber spectra, as in Le Traon et al. [2008] and Xu and $F u[2011,2012]$. We will take advantage of the frequent temporal sampling of HYCOM to separate the spectra into low- and high-frequency components. We use a 48 $\mathrm{h}$ cutoff to delineate between high and low frequencies. The high-frequency component, which is dominated by internal waves and tides, may be considered as noise, if one is interested primarily in the spectra of low-frequency geostrophic motions. Of interest as well is whether the spectral slopes of the full velocity field, which includes ageostrophic motions, are greatly different from slopes for the geostrophic velocity estimated from the $\mathrm{SSH}$ assuming a geostrophic balance.

[11] In Figures 3a and 3b we display the HYCOM wavenumber spectra of SSH from the Gulf Stream $\left(35^{\circ} \mathrm{N}, 305^{\circ} \mathrm{E}\right)$ and Kuroshio $\left(35^{\circ} \mathrm{N}, 155^{\circ} \mathrm{E}\right)$, both high EKE regions. The eddies are so energetic in these regions that the estimation of spectral slopes in the mesoscale band is virtually unaffected by the presence of high-frequency motions such as tides; note the near-overlap of the blue (low-frequency) and black (total) SSH spectra in the figures. The least squares SSH slope over the fixed mesoscale band is $-4.0 \pm 0.5$ in the Gulf Stream region, which is very close to predictions of SQG turbulence and consistent with results in Le Traon et al. [2008] and Sasaki and Klein [2012]. The least squares SSH slope is $-4.4 \pm 0.4$ in the Kuroshio, which lies between the predictions of SQG and QG turbulence. Both regions 


\section{(a) Along-track satellite altimeter data}

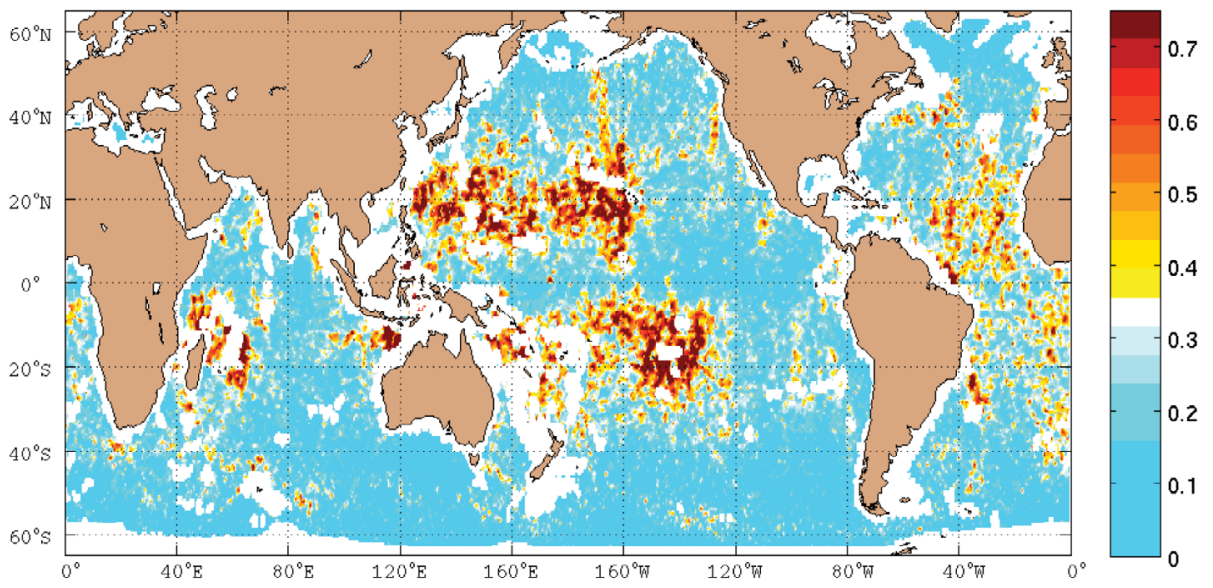

\section{(b) HYCOM}

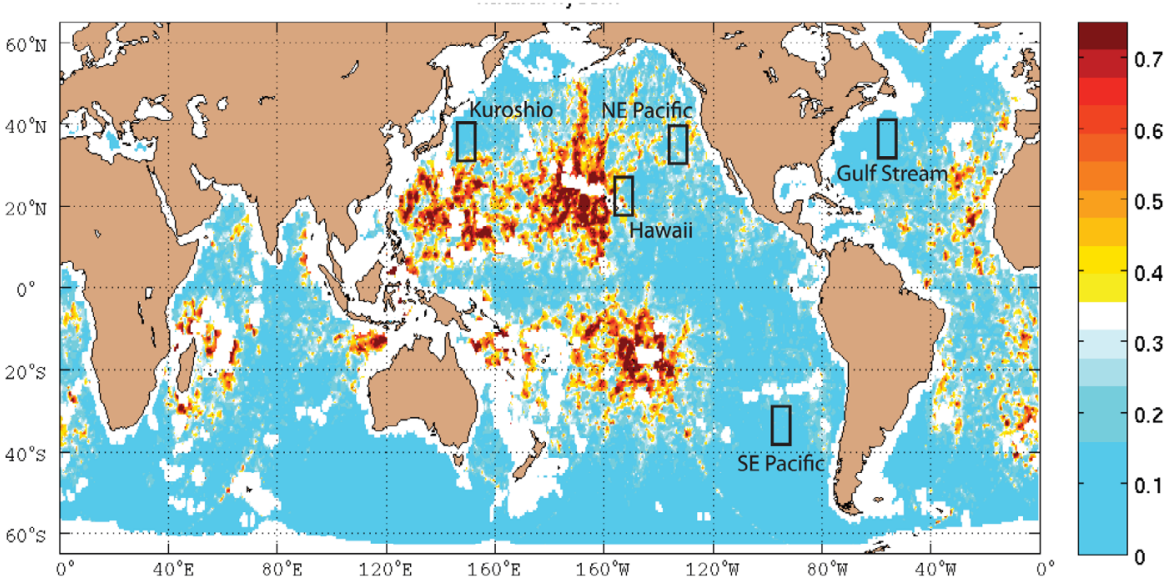

Figure 2. Internal tide signature in $\mathrm{M}_{2}$ sea surface elevation amplitudes (cm) in (a) along-track altimeter data [Ray and Mitchum, 1996, 1997; Ray and Byrne, 2010] and in (b) HYCOM. The internal tide signature is determined from band-passing 50-400 km wavelengths in the $\mathrm{M}_{2}$ sea surface elevations; absolute values of the band-passed results are shown. Boxes indicate regions over which wavenumber spectra are computed in Figures 3-5.

show slopes flatter than predictions of QG turbulence, again, consistent with results in Le Traon et al. [2008] and Sasaki and Klein [2012]. For the high frequency motions a peak around $160 \mathrm{~km}\left(6 \times 10^{-6} \mathrm{cpm}\right)$, the expected wavelength of a first baroclinic mode $\mathrm{M}_{2}$ internal wave, is observed, but it is much weaker than the low frequency $\mathrm{SSH}$ at the same wavelengths.

[12] In Figure 4 we display the spectrum of kinetic energy in the Kuroshio region $\left(35^{\circ} \mathrm{N}, 155^{\circ} \mathrm{E}\right)$. The $-2.5 \pm 0.4$ slope of the spectrum of the total KE (Figure 4a) falls between the SQG and QG slope prediction, while the slope of the low frequency $\mathrm{KE}$ is slightly steeper at $-2.7 \pm 0.4$. With $\mathrm{KE}$ as with $\mathrm{SSH}$, the high frequency spectrum in the Kuroshio region is much weaker than the low frequency spectrum. As can be seen in Figure 4b, for high EKE regions such as the Kuroshio, the KE estimated from the $\mathrm{SSH}$, assuming geostrophy and isotropy for the low frequency height and velocity, compares well in the mesoscale band with actual KE spectrum obtained from the surface velocity. The major differences occur at long wavelengths where the total $\mathrm{KE}$ is greater and short wavelengths where the isotropic geostrophic $\mathrm{KE}$ is greater.

[13] A very different picture emerges in regions where internal tide activity is strong and mesoscale eddy activity is weak. In Figure 5, we display wavenumber spectra in the three regions in the interior of the Pacific (away from western boundary currents) shown in Figure 2b. North of Hawai'i $\left(25^{\circ} \mathrm{N}, 210^{\circ} \mathrm{E}\right)$, a hot spot for internal tide generation, the high frequency SSH variance exceeds the low frequency variance for the mesoscale band (Figure 5a). A peak associated with the first mode baroclinic $\mathrm{M}_{2}$ tide is clearly visible around $160 \mathrm{~km}$. The slope of the SSH wavenumber 
(a)

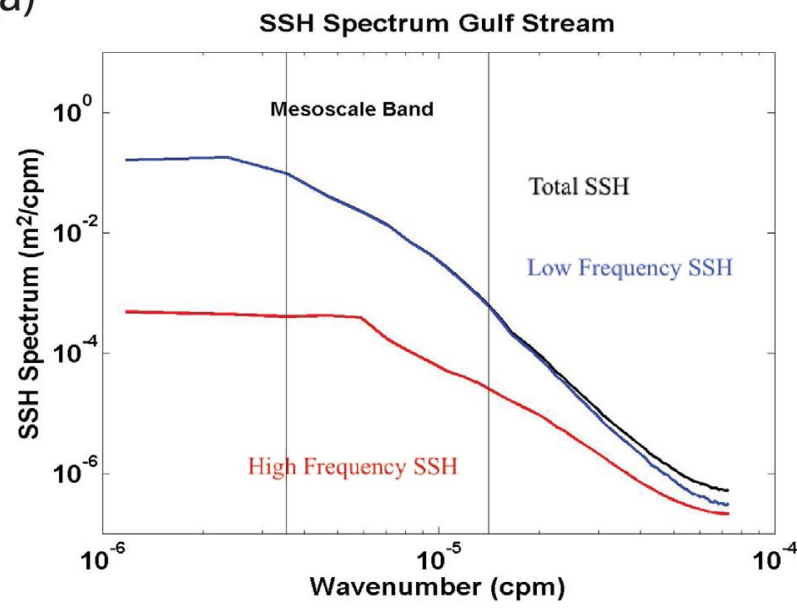

(b)

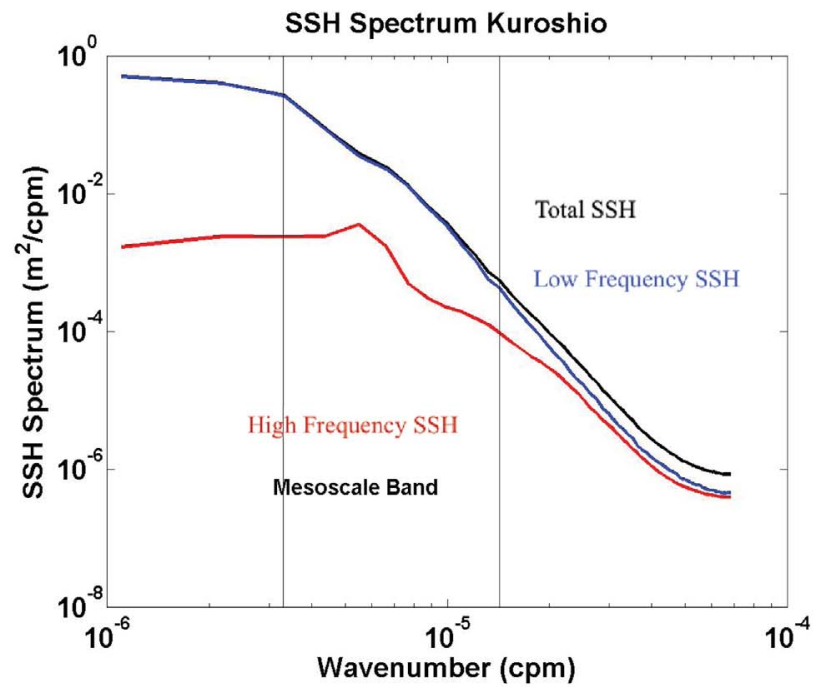

Figure 3. Wavenumber spectrum of sea surface height in high EKE regions of (a) the Gulf Stream $\left(35^{\circ} \mathrm{N}, 305^{\circ} \mathrm{E}\right)$ and (b) the Kuroshio $\left(35^{\circ} \mathrm{N}, 155^{\circ} \mathrm{E}\right)$ from the marked boxes in Figure 2b. Spectra of total (black), low frequency (blue), and high frequency (red) SSH are shown. In this figure, as in the rest of this paper, the mesoscale band is defined from 70 to $250 \mathrm{~km}$ as in $\mathrm{Xu}$ and $\mathrm{Fu}$ [2011]. In this band the least squares slopes of the total SSH spectra for the mesoscale band are $-4.0 \pm 0.5$ and $-4.4 \pm 0.4$ in the Gulf Stream and Kuroshio, respectively.

spectrum for the fixed mesoscale band is $-2.8 \pm 0.4$, when the internal waves are included, but the slope of the low frequency height is steeper at $-4.4 \pm 0.2$, falling between the predictions from SQG and QG turbulence. Similar results are obtained for the KE (not shown), where the slope steepens from $-0.9 \pm 0.2$ for the total KE to $-2.4 \pm 0.2$ for the low frequency KE. Thus, when internal waves are removed, the slope of both SSH and KE falls between the predicted QG and SQG turbulence slope. In the Northeast Pacific $\left(35^{\circ} \mathrm{N}, 230^{\circ} \mathrm{E}\right.$, Figure $\left.5 \mathrm{c}\right)$, the high and low frequency SSH variance are nearly the same with the slope of the total SSH flatter than the low frequency SSH slope at $-2.9 \pm 0.8$ and $-3.5 \pm 0.4$, respectively, the latter being slightly less than the SQG slope. In the Southeast Pacific $\left(35^{\circ} \mathrm{S}, 265^{\circ} \mathrm{E}\right.$, Figure $\left.5 \mathrm{e}\right)$, where the high frequency $\mathrm{SSH}$ variance is very weak, the SSH spectral slopes are flatter than the SQG expectation of $-11 / 3$ at $-2.7 \pm 0.4$ for both the total SSH and low frequency SSH.

[14] For QG and SQG turbulence, the shape of the spectra is determined by the energy and enstrophy cascades over an inertial sub-range. QG theory assumes baroclinic energy is input into the ocean at large mesoscales and cascades toward

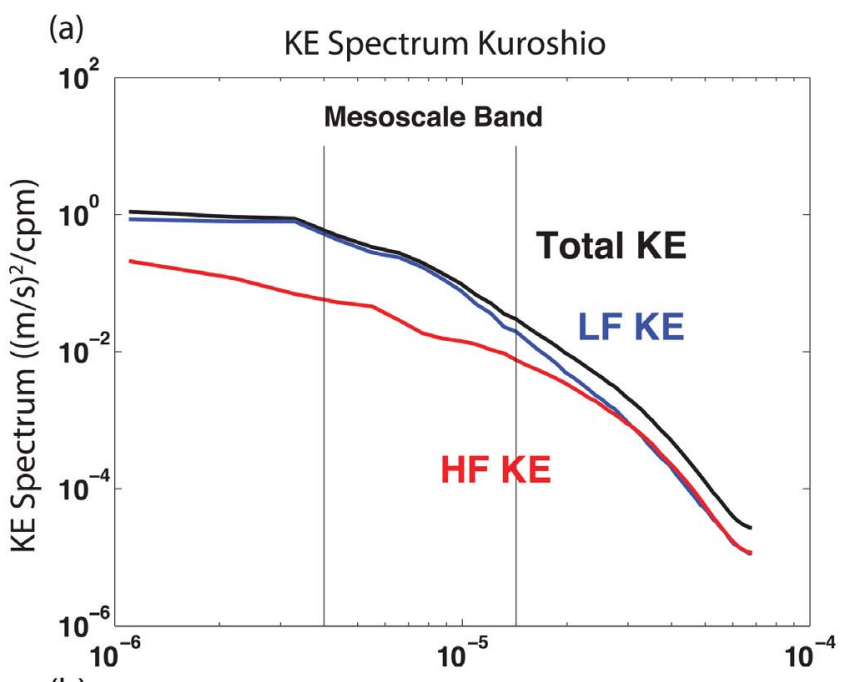

(b)

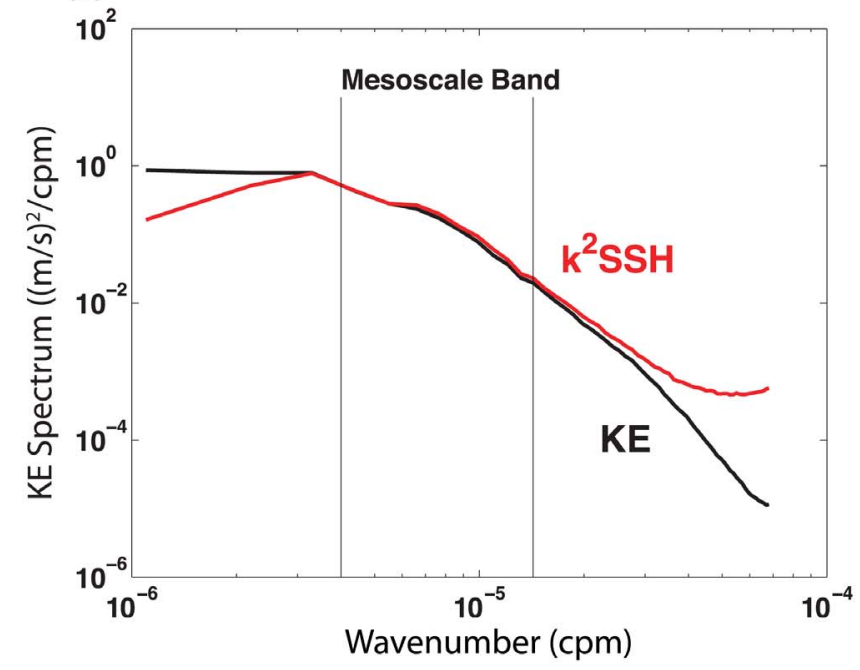

Figure 4. Wavenumber spectrum of kinetic energy in Kuroshio region $\left(35^{\circ} \mathrm{N}, 150^{\circ} \mathrm{E}\right)$. (a) Spectra of $\mathrm{KE}$ computed from model velocities, including ageostrophic and geostrophic flows, and divided into total (black), low frequency (blue), and high frequency (red) components. The least squares slope of total KE in the mesoscale band is $-2.3 \pm 0.3$, while the slope of the low frequency $\mathrm{KE}$ is slightly steeper at $-2.5 \pm 0.4$. (b) Wavenumber spectra computed from model velocities (black) and from SSH assuming geostrophy and isotropy (red) are nearly identical in the mesoscale band (70-250 km) with the isotropic geostrophic KE less at long wavelengths and greater at short wavelengths. 

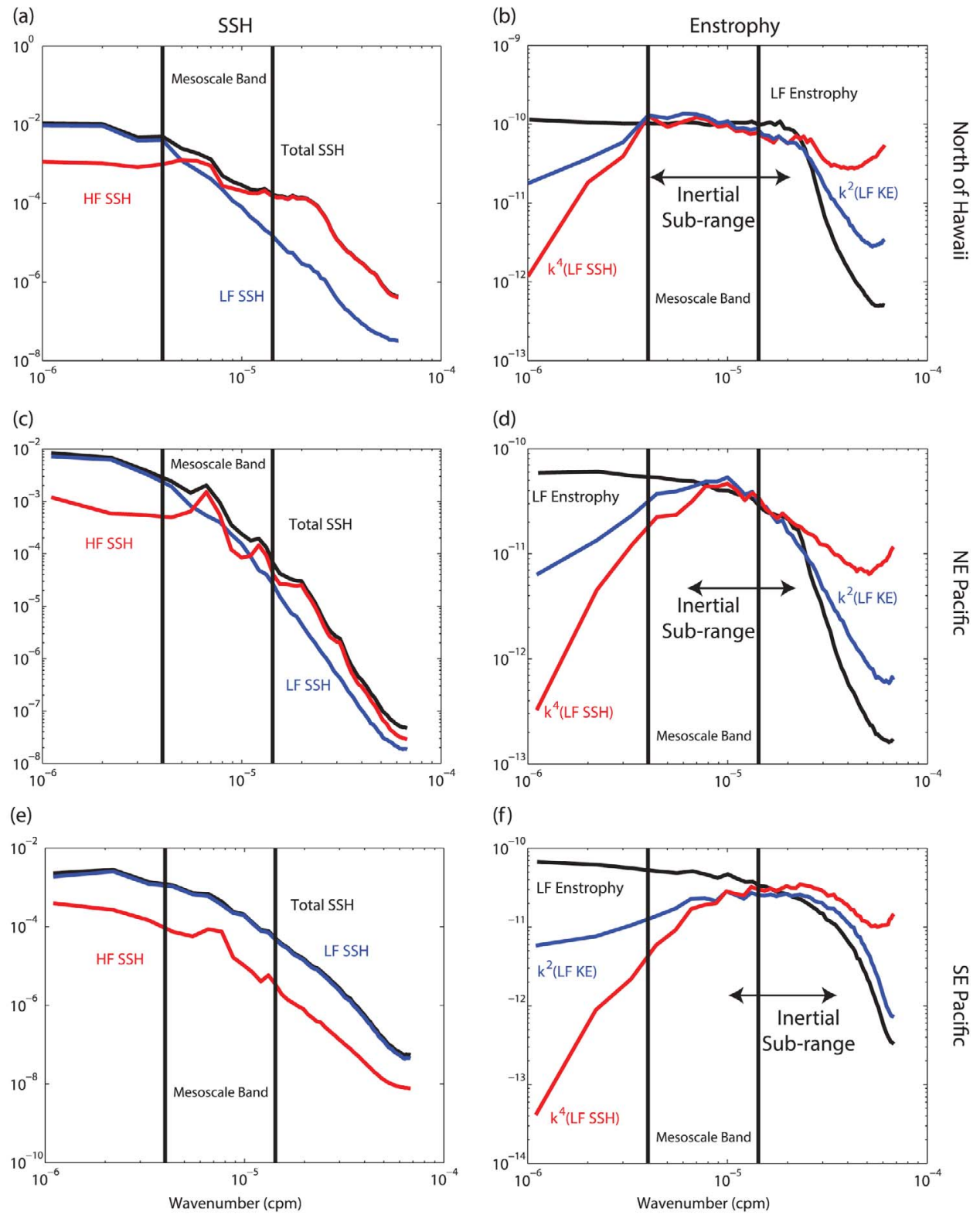

Figure 5. Wavenumber spectrum of sea surface height and enstrophy in three interior Pacific, lower EKE boxes shown in Figure 2: (a, b) region north of Hawai'i $\left(25^{\circ} \mathrm{N}, 210^{\circ} \mathrm{E}\right),(\mathrm{c}, \mathrm{d})$ Northeast Pacific region $\left(35^{\circ} \mathrm{N}, 230^{\circ} \mathrm{E}\right)$, and (e, f) Southeast Pacific region $\left(35^{\circ} \mathrm{S}, 265^{\circ} \mathrm{E}\right)$. The spectra of total SSH (black), low frequency SSH (blue), and high frequency SSH (red) are shown in the left hand panels. The enstrophy spectra from the low frequency vorticity (black), the isotropic vorticity estimated from the low frequency kinetic energy (blue) and the isotropic vorticity estimated from the low frequency SSH (red) are shown in the right hand panels. Notice the shift in the enstrophy toward shorter wavelength as the EKE level decreases.

the Rossby radius, where the baroclinic flow is transferred to the barotropic mode and an inverse cascade of energy to large scales occurs [Salmon, 1980]. Enstrophy cascades to small scales. For QG turbulence, while the KE spectrum decreases steeply with wavenumber, the enstrophy spectrum is much flatter varying as $\mathrm{k}^{-1}$. For SQG turbulence, where frontogenesis near the boundary dominates, the enstrophy spectrum increases slightly with wavenumber. The enstrophy spectra in the low EKE regions of the Pacific (Figures 5b, 5d, and 5f) all exhibit relatively flat spectra for a limited range of wavenumbers, falling between the expectations of the QG and SQG theory. Over this limited range, the isotropic, geostrophic enstrophy spectral estimates obtained from the KE and SSH spectra are similar to the spectra obtained from the vorticity of the low frequency velocity. The isotropic estimates are smaller at small wavenumbers than the enstrophy from the low-frequency velocity with a broad, weak maximum before a steep decrease with increasing wavenumber. As the EKE decreases from Figure $5 \mathrm{~b}$ to Figure $5 \mathrm{f}$, the wavenumber band of the broad 


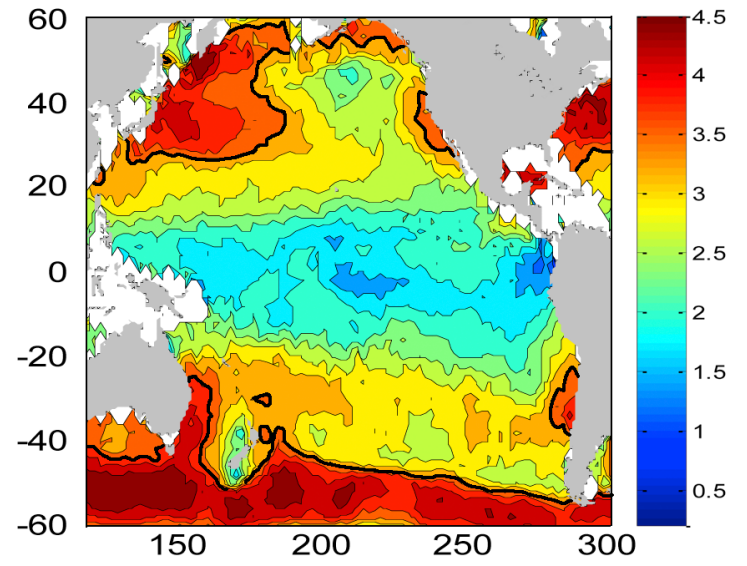

Figure 6. Slope of the noise-corrected along track satellite altimeter SSH wavenumber spectrum in the North Pacific for a 70-250 km band, adapted from $X u$ and $F u$ [2012]. All slopes multiplied by -1 to make them positive. Slopes flatter than $-11 / 3$ (colors coolers than the enhanced dark contour) represent regions inconsistent with QG or SQG theory.

maximum shifts to large wavenumbers (smaller scales). If we use the broad maximum of the enstrophy spectrum as an indicator of the inertial sub-range, then we can recalculate the $\mathrm{SSH}$ and KE slopes over the new wavenumber band rather than the fixed $70-250 \mathrm{~km}$ band used by $X u$ and $F u$ [2011, 2012]. North of Hawai'i $\left(25^{\circ} \mathrm{N}, 210^{\circ} \mathrm{E}\right.$, Figures 5a and $5 \mathrm{~b}$ ), the slopes remain unchanged as the fixed band is contained within the new sub-range. In the Northeast Pacific $\left(35^{\circ} \mathrm{N}, 230^{\circ} \mathrm{E}\right.$, Figures $5 \mathrm{c}$ and $\left.5 \mathrm{~d}\right)$, the low-frequency $\mathrm{SSH}$ slope steepens from $-3.5 \pm 0.4$ over the fixed band to $-4.9 \pm 0.4$ over the new inertial sub-range of $50-150 \mathrm{~km}$. Similarly, the low-frequency KE slope steepens from $-1.9 \pm 0.3$ over the fixed band to $-3.2 \pm 0.3$ for the shifted sub-range. In the Southeast Pacific $\left(35^{\circ} \mathrm{S}, 265^{\circ} \mathrm{E}\right.$, Figures $5 \mathrm{e}$ and $5 \mathrm{f}$ ), the EKE is even lower and the inertial sub-range is shifted to even smaller scales, approximately $33-125 \mathrm{~km}$. The low-frequency SSH slope steepens from $-2.7 \pm 0.4$ for the fixed band to $-3.8 \pm 0.2$ over the new sub-range, while the low-frequency $\mathrm{KE}$ slope steepens from $-1.5 \pm 0.2$ to $-2.1 \pm 0.1$. Based upon the shifted inertial sub-ranges, the low-frequency SSH and KE slopes fall between the expectations of SQG and QG turbulence.

[15] Next we display maps of spectral slopes for $50 \%$ overlapping $10^{\circ}$ by $10^{\circ}$ boxes in the North Pacific Ocean from the HYCOM simulation with tides. For the sake of comparison, we first show, in Figure 6, the slope of the SSH wavenumber spectrum in the Pacific Ocean, computed from along track altimeter data with the altimeter noise correction of $X u$ and $F u$ [2012]. As they noted, the wavenumber slopes nearly equal those predicted by SQG turbulence $(-11 / 3)$ in high eddy energy regions such as western boundary currents, but for most of the Pacific Ocean the spectral slopes are much flatter than $-11 / 3$. In Figure 6 , the $-11 / 3$ slope contour is thickened to distinguish the type 1 and 2 regions of $X u$ and $F u[2011,2012]$ as colors warmer than dark orange with slopes equal or greater than expected for SQG turbulence and type 3 and 4 regions with colors cooler than light orange and slopes less than QG or SQG turbulence.
A similar map for the HYCOM SSH (Figure 7a) has much steeper slopes than the noise-corrected altimeter slopes, exceeding $-11 / 3$ for most of the Pacific Ocean. However, in the subtropics north of Hawai'i, subpolar western North Pacific and eastern South Pacific, the HYCOM spectral slopes are much flatter than HYCOM slopes in the rest of the Pacific. The map for the HYCOM KE (Figure 8a) is similar with slopes steeper than $-5 / 3$ for most of the Pacific Ocean, except for the subtropics north of Hawai'i and subpolar North and South Pacific. The Hawaiian Islands are a hot spot of generation of internal tides. In the spectra shown in Figure 5a, the high frequency motions dominate the $\mathrm{SSH}$ spectrum, but the low frequency SSH spectrum has a much steeper slope. Maps of the low-passed HYCOM SSH (Figure 7b) and KE (Figure 8b) spectral slopes show an increase in slope over the entire Pacific Ocean compared to

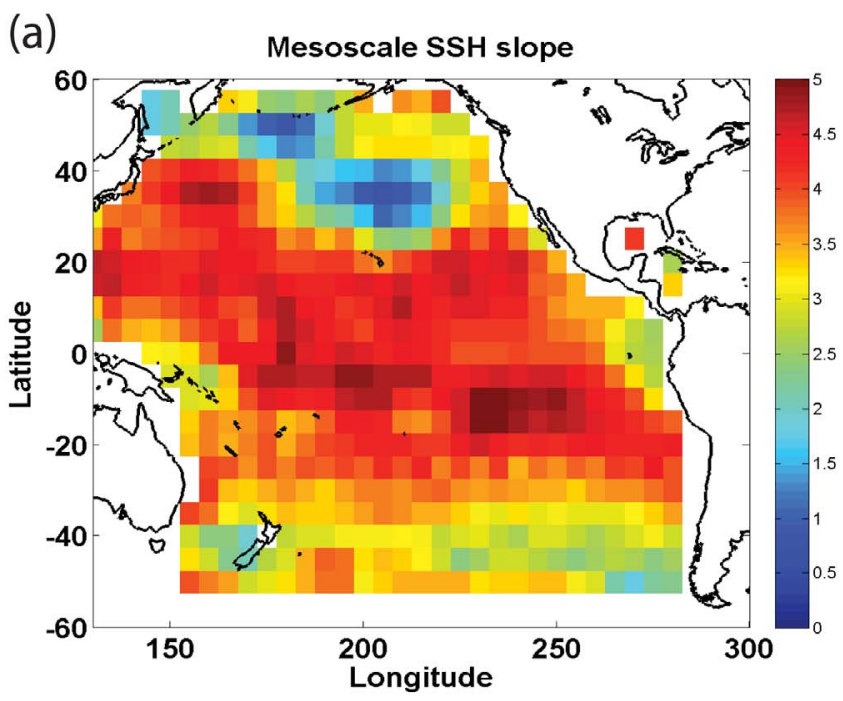

(b)

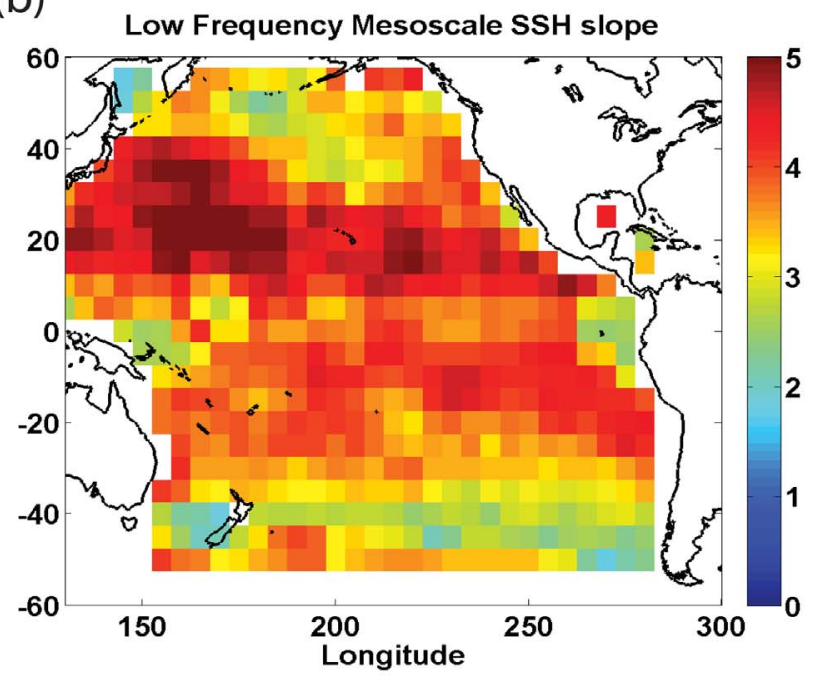

Figure 7. Least squares estimate of the slope of the SSH wavenumber spectrum in the North Pacific, computed over a 70-250 km band in HYCOM. Slopes are computed from spectra of (a) total SSH and (b) low frequency SSH. As in Figure 6 , all slopes are multiplied by -1 to make them positive. 


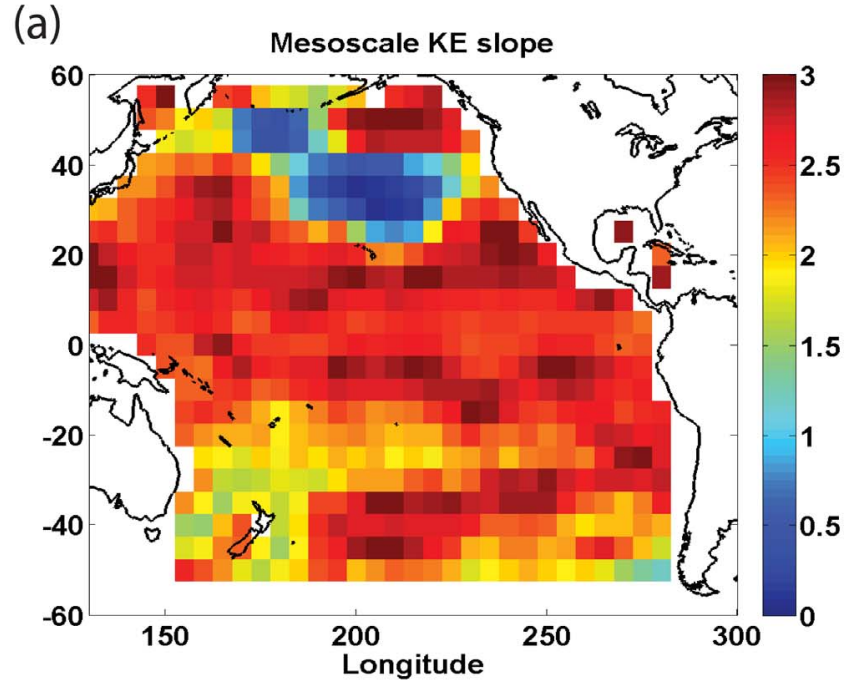

(b)

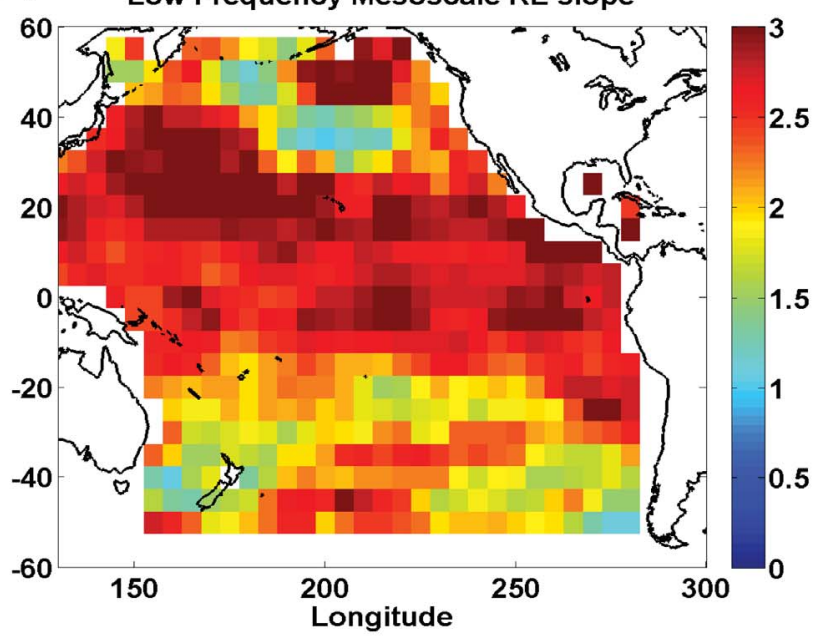

Figure 8. Least squares estimate of the slope of the KE wavenumber spectrum in the North Pacific, computed over a 70-250 km band in HYCOM. Slopes are computed from spectra of (a) total KE and (b) low frequency KE. As in Figure 6 and 7, all slopes are multiplied by -1 to make them positive.

maps made from the total (high- plus low-frequency quantities (Figures $7 \mathrm{a}$ and $8 \mathrm{a}$ ). However, we still find regions with slopes much flatter than expected for either QG or SQG turbulence. Also, there are regions where the lowfrequency slopes are not significantly different from the slopes based upon the total SSH and KE. These regions tend to be areas with weak EKE in the general circulation. The flatter slopes in such regions may be an artifact arising from the estimation of the slope across a fixed wavenumber band. As noted for Figure 5, as the EKE decreases, the broad maximum of the enstrophy spectrum shifts to smaller scales. Estimating the spectral slopes over the shifted subrange steepen the slopes. Additionally, the length scales of eddies change with latitude [Stammer, 1997]. Thus, the wavenumber band chosen in $X u$ and $F u$ [2011] and which is followed here for computing slopes is not dynamically equivalent across all latitudes.
[16] Because the broad maximum of the enstrophy spectrum in regions of low EKE shifts to smaller scales than the fixed 70-250 km band, the 70-250 km wavelength band chosen, in $X u$ and $F u$ [2011, 2012] and here, to compute slopes over does not always lie in a cascade dominated regime. To characterize the potential shift in the inertial subrange, we calculate the peak of the broad maximum of the enstrophy spectrum. For the broad enstrophy maximum, the estimates from the low-frequency vorticity and the isotropic, geostrophic estimates from the KE and SSH are similar (Figures 5b, 5d, and 5f), but the maximum is easier to see in the geostrophic estimates. Thus, the peak vorticity scale defined as the wavelength of the maximum of the enstrophy spectrum, shown in Figure 9, is calculated using the isotropic, geostrophic vorticity estimate derived from the $\mathrm{KE}$ spectrum. All regions with spectral slopes less than the predicted SQG slope for the low-frequency SSH and KE in Figures $7 \mathrm{~b}$ and $8 \mathrm{~b}$ are regions where the peak of the enstrophy spectrum occurs at scales less than $100 \mathrm{~km}$. Sasaki and Klein [2012] point out the importance of the difference of the wavenumber of the peak of the relative vorticity spectrum compared to the peak of the energy spectrum. For the low EKE Northeast Pacific region (Figure 5d), the peak of the enstrophy spectrum is near $120 \mathrm{~km}$, while the peak in the energy spectrum is at much longer wavelengths, near $300 \mathrm{~km}$. In the even weaker EKE Southeast Pacific (Figure $5 \mathrm{f}$ ), the shift in the peak of the enstrophy spectrum to shorter wavelengths is even more pronounced. Thus the $70-250 \mathrm{~km}$ mesoscale band does not span the cascading regime for all locations.

\section{Why Do the Slope Maps Between the Model and the Altimeter Differ So Much?}

[17] The altimeter SSH wavenumber spectral slopes differ substantially from the model spectral slopes and the predictions of QG and SQG turbulence theory for most of the

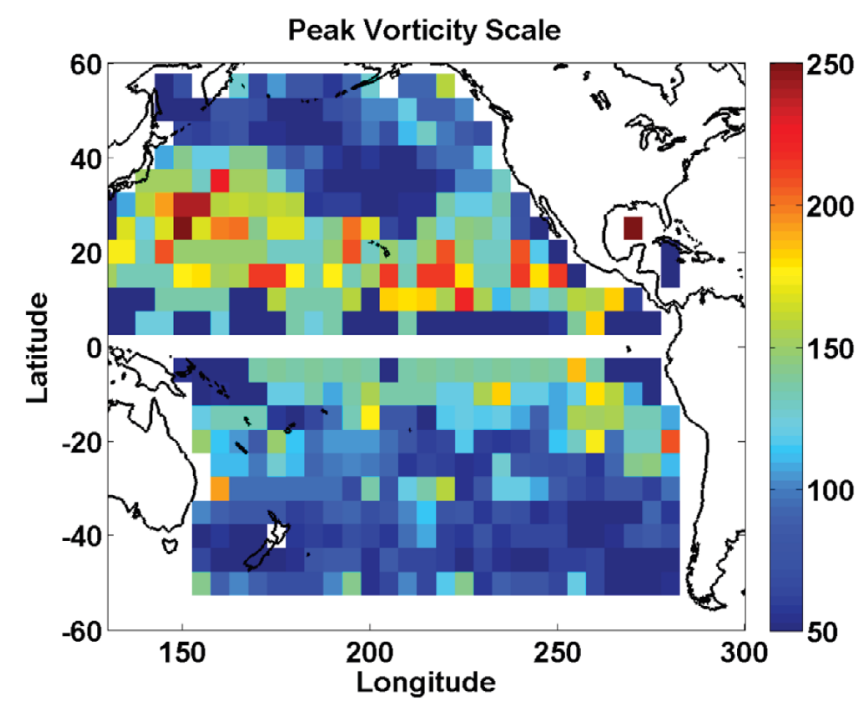

Figure 9. Map of the peak vorticity scale $(\mathrm{km})$ in HYCOM, used as a proxy to show the shift of the inertial sub-range to smaller scales with decreasing eddy kinetic energy. 


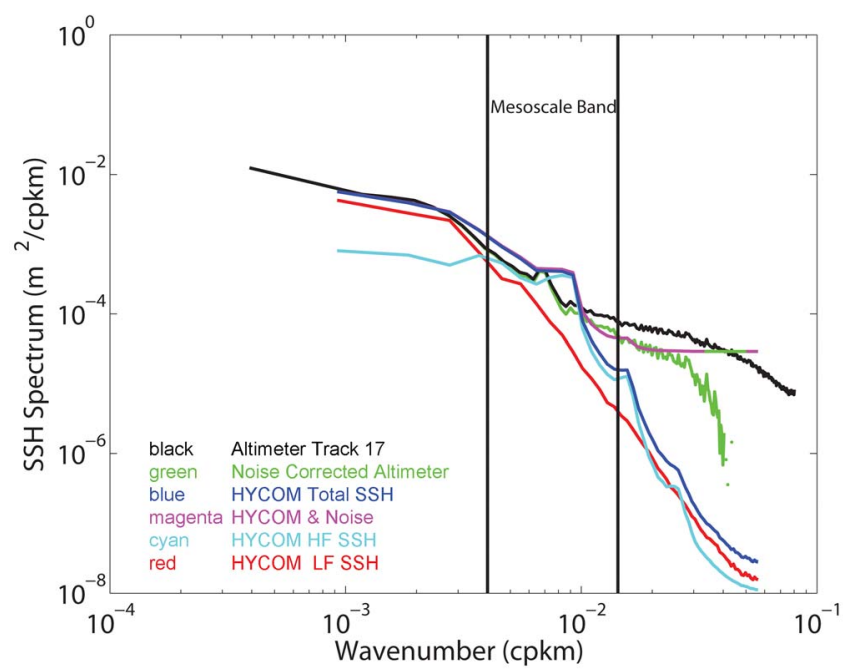

Figure 10. Impact of noise on the estimation of wavenumber spectral slopes for along-track altimeter $\mathrm{SSH}$ (Track 17) and model SSH spectra at $10^{\circ} \mathrm{S}, 260^{\circ} \mathrm{E}$. For the model, wavenumber spectra of the total (blue), high frequency (cyan) and low frequency (red) SSH are compared to the observed altimeter SSH in black and the noise corrected altimeter (green). If the altimeter noise is added to the spectrum of HYCOM SSH (magenta), the resulting spectrum is comparable to the spectrum of altimeter $\mathrm{SSH}$ (black). Similarly, the noise corrected altimeter (green) is comparable to the model total SSH (blue).

Pacific Ocean. There are a number of possible reasons for the differences. Internal waves have a flat wavenumber spectrum which, when combined with the low-frequency SSH or velocity, leads to a flattening of the spectral slopes over the fixed mesoscale band. The degree of flattening depends upon the relative strength of the high-frequency internal wave to QG motion. In addition, the difference between the model and altimeter spectral slope maps may be an artifact of the estimation over a fixed mesoscale band, which does not account for changes in the Rossby radius with latitude and shifts in the inertial sub-range with EKE.

[18] The model spectra decay rapidly with increasing wavenumber, while the altimeter spectra are flat at high wavenumber (altimeter track 17 centered on $10^{\circ} \mathrm{S}, 260^{\circ} \mathrm{E}$, black line in Figure 10). The flat high wavenumber tail of the altimeter spectrum may represent the noise floor for the altimeter as pointed out by Le Traon et al. [2008] and Xu and $F u$ [2012]. Adding white noise comparable to the altimeter noise floor to the model $\mathrm{SSH}$ yields a spectrum which is very similar to the observed altimeter $\mathrm{SSH}$ (magenta line in Figure 10). Similarly, removing the noise floor from the altimeter spectrum yields a spectrum similar to the model total SSH (green line in Figure 10). Even correcting for the altimeter noise doesn't steepen the spectrum as much as low-passing the model SSH does (red line in Figure 10). In the high EKE regions, the energy in the mesoscale band is much greater than the noise floor and the spectral slope lies between the prediction of QG and SQG turbulence theory, while the noise flattens the spectral slope in lower EKE regions. Thus, the difference between the model and altimeter spectral slope estimates may have both dynamical causes due to internal waves and the characteristics of the energy and enstrophy cascades as well as instrumental causes.

\section{Implications for Wide-Swath Satellite Altimetry}

[19] Internal tides have significant energy at mesoscale wavelengths. Because internal tides are aliased by the long repeat sampling times of altimeters, a wide swath altimeter [Fu and Ferrari, 2008; Fu et al., 2012], like current generation nadir altimeters, will have some difficulty distinguishing between long internal tides and mesoscale eddies.

[20] The SSH field observed by a wide swath altimeter will contain variability from both mesoscale eddies and lowmode internal tides. Depending upon the relative strength of the internal tides and mesoscale eddies, the SSH field may be dominated by either class of motion. Since the low-mode internal tides have similar length scales as mesoscale eddies, the two classes of motion cannot be separated in a single snapshot. Using multiple snapshots, it may be possible to separate the geostrophic height field from the internal tides.

[21] Ray and Zaron [2011] found that the low mode internal tides are nearly stationary over much of the ocean. Analysis of the model SSH shows that the internal tides fluctuate by only $0.2 \mathrm{~cm}$ RMS over much of the tropical and midlatitude oceans. Thus it may be possible to extract the stationary tides from the instantaneous height maps to reduce the impact of the internal tides on estimates of spectral slopes due to low-frequency motions.

[22] The dynamics of the upper ocean cannot be inferred from wavenumber slope of the $\mathrm{SSH}$ of velocity without paying close attention to the scales of the peaks of the energy and enstrophy spectra. The assumption of isotropy and geostrophy does yield consistent spectra for kinetic energy and enstrophy for the low-frequency flow.

\section{Summary and Discussion}

[23] In this paper we have computed wavenumber spectra in the mesoscale band of 70-250 km from new HYCOM runs which concurrently simulate the eddying general circulation, barotropic tides, and baroclinic (internal) tides [Arbic et al., 2010, 2012]. We are motivated by recent discussions of the wavenumber spectra of sea surface height and velocity predicted by SQG versus QG turbulence, the likelihood that the planned wide-swath satellite altimeter will measure these spectra much better than current generation nadir altimeters, and the certainty that aliasing of internal tidal motions will affect spectra computed from wide-swath as well as current generation nadir altimeters.

[24] When the wavenumber spectra of SSH and KE are estimated near the generating regions of internal tides, the resulting spectra are much flatter than the expectations of QG or SQG theory. This shows that in locations of energetic internal tides, the slope of the $\mathrm{SSH}$ or $\mathrm{KE}$ wavenumber spectrum in the mesoscale band cannot be used to infer the ocean dynamics unless the internal tides are accurately removed. For the HYCOM simulations with embedded tides, we can use the frequent (one-hour) sampling to separate high- and low-frequency motions more cleanly than is possible in altimeter data. If the height and velocity variability 
are separated into low frequency (periods greater than $48 \mathrm{~h}$ ) and high frequency (periods less than a day), then a different pattern emerges with a flat wavenumber spectrum at high frequency and a steeper wavenumber spectrum at low frequency. Away from generating regions, in locations where the internal waves are weaker than the QG flow, then the high frequency motions have little impact on the wavenumber spectrum. The global pattern of the slope of the mesoscale wavenumber spectrum, while showing regions of small, flatter slopes, does not agree quantitatively with the recent results of $X u$ and $F u$ [2011] for the along track SSH wavenumber spectrum, which show very flat slopes away from regions of energetic eddies. Recently, $X u$ and $F u$ [2012] have recomputed their spectral slopes after accounting for noise, and have obtained less flat results, closer to results shown here and Sasaki and Klein [2012] than their original results. Low-passing the SSH and velocity yields spectra which lie between the expected slopes for Quasi-Geostrophic (QG) turbulence and Surface QuasiGeostrophic (SQG) turbulence. Even after removing the internal wave signal from the SSH and velocity, the spectral slopes can be flatter than either the QG or SQG predicted slope when estimated using a fixed mesoscale band. Altimeter noise affects the slope in the quieter mesoscale regions, which may explain differences between the model and altimeter spectra in some regions, for instance the tropics.

[25] The results of the HYCOM simulations with embedded tides presented here have already been used in the planning of AirSWOT, an airborne campaign to test the technology of the wide-swath altimeter. We showed that in our model the low-frequency motions dominate the wavenumber spectra in the planned AirSWOT campaign regions off of California and the Mediterranean coast. This suggests that tides will not significantly contaminate the signals in those campaigns, which will not run long enough to extract tides via harmonic analysis (E. Rodriguez, personal communication, 2011).

[26] Determining whether QG or SQG dynamics govern the upper ocean requires an evaluation of the energy and enstrophy cascades in addition to the shape of the wavenumber spectra. Regions with flat spectral slopes, even after low-passing, tend to be regions with low EKE and peak vorticity at small scales, meaning that the cascade of enstrophy to still smaller scales lies outside the 70-250 km band chosen for computing slopes in $X u$ and $F u$ [2011, 2012] and in this study. A similar point has been made in Sasaki and Klein [2012]. The model resolution may not be adequate to characterize the small scale dynamics of the upper ocean. Sasaki and Klein [2012] find a forward energy cascade for scales smaller than $30 \mathrm{~km}$ in low EKE regions (see their Figure 7), which suggests submesoscale dynamics may be important. Thoppil et al. [2011] find the EKE in the $1 / 12.5^{\circ}$ model to be deficient relative to surface drifters, while the $1 / 25^{\circ}$ model was much closer to the observations at all depths. Lévy et al. [2012] find a similar result in an idealized resolution study, where the $1 / 9^{\circ}$ model has a steeper spectral slope and decreased energy at scales smaller than $70 \mathrm{~km}$ compared to $1 / 27^{\circ}$ and $1 / 54^{\circ}$ resolution simulations. A new simulation with doubled horizontal resolution and increased vertical resolution along with improvements to the topographic drag and boundary conditions is planned, but the cost and size of this calculation make further analysis beyond the scope of this paper. Klein et al. [2008] note that some of the local spectral relationships between KE, SSH and density are found in regions where the Rossby number is large and SQG dynamics should not dominate. Thus, the existence of QG or SQG turbulent equilibria may not be confirmed from the spectral slopes, but requires a deeper investigation into the model dynamics.

[27] Acknowledgments. We thank Rosemary Morrow and Ernesto Rodriguez for suggesting the calculation of wavenumber spectra in our concurrent HYCOM wind-plus-tides simulations. BKA acknowledges funding provided by Naval Research Laboratory contract N000173-06-C002 and Office of Naval Research grant N00014-11-1-0487. JGR, JFS, EJM, and AJW were supported by the projects "Eddy resolving global ocean prediction including tides" and "Ageostrophic vorticity dynamics" sponsored by the Office of Naval Research under program element $0602435 \mathrm{~N}$. This work was supported in part by a grant of computer time from the DOD High Performance Computing Modernization Program at the Navy DSRC. This is NRL contribution NRL/JA/7320-12-1280 and has been approved for public release.

\section{References}

Arbic, B. K., S. T. Garner, R. W. Hallberg, and H. L. Simmons (2004), The accuracy of surface elevations in forward global barotropic and baroclinic tide models, Deep Sea Res., Part II, 51, 3069-3101, doi:10.1016/ j.dsr2.2004.09.014.

Arbic, B. K., A. J. Wallcraft, and E. J. Metzger (2010), Concurrent simulation of the eddying general circulation and tides in a global ocean model, Ocean Modell., 32, 175-187, doi:10.1016/j.ocemod.2010.01.007.

Arbic, B. K., J. G. Richman, J. F. Shriver, P. G. Timko, E. J. Metzger, and A. J. Wallcraft (2012), Global modeling of internal tides within an eddying ocean general circulation model, Oceanography, 25, 20-29, doi:10.5670/oceanog.2012.38.

Carrère, L., C. Le Provost, and F. Lyard (2004), On the statistical stability of the $\mathrm{M}_{2}$ barotropic and baroclinic tidal characteristics from along-track Topex/Poseidon satellite altimetry analysis, J. Geophys. Res., 109, C03033, doi:10.1029/2003JC001873.

Cartwright, D. E. (1999), Tides: A Scientific History, 192 pp., Cambridge Univ. Press, Cambridge, U. K.

Chassignet, E. P., H. E. Hurlburt, O. M. Smedstad, G. R. Halliwell, P. J. Hogan, A. J. Wallcraft, R. Baraille, and R. Bleck (2007), The HYCOM (HYbrid Coordinate Ocean Model) data assimilative system, J. Mar. Syst., 65, 60-83, doi:10.1016/j.jmarsys.2005.09.016.

Egbert, G. D., and R. D. Ray (2000), Significant dissipation of tidal energy in the deep ocean inferred from satellite altimeter data, Nature, 405, 775-778, doi:10.1038/35015531.

Egbert, G. D., A. F. Bennett, and M. G. G. Foreman (1994), TOPEX/ POSEIDON tides estimated using a global inverse model, J. Geophys. Res., 99, 24,821-24,852, doi:10.1029/94JC01894.

Egbert, G. D., R. D. Ray, and B. G. Bills (2004), Numerical modeling of the global semidiurnal tide in the present day and in the last glacial maximum, J. Geophys. Res., 109, C03003, doi:10.1029/2003JC001973.

Fu, L.-L., and A. Cazenave (Eds.) (2001), Satellite Altimetry and Earth Sciences: A Handbook of Techniques and Applications, Academic, New York.

Fu, L.-L., and R. Ferrari (2008), Observing oceanic submesoscale processes from space, Eos Trans. AGU, 89(48), 488, doi:10.1029/2008EO480003. Fu, L.-L., D. Alsdorf, R. Morrow, E. Rodriguez, and N. Mognard (Eds.) (2012), SWOT: The Surface Water and Ocean Topography Mission: Wide-Swath Altimetric Measurement of Water Elevation on Earth, JPLPublication 12-05, 228 pp., Jet Propul. Lab., Pasadena, Calif.

Garner, S. T. (2005), A topographic drag closure built on an analytical base flux, J. Atmos. Sci., 62, 2302-2315, doi:10.1175/JAS3496.1.

Hendershott, M. C. (1972), The effects of solid earth deformation on global ocean tides, Geophys. J. R. Astron. Soc., 29, 389-402, doi:10.1111/ j.1365-246X.1972.tb06167.x.

Jayne, S. R., and L. C. St. Laurent (2001), Parameterizing tidal dissipation over rough topography, Geophys. Res. Lett., 28, 811-814, doi:10.1029/ 2000GL012044

Kara, A. B., A. J. Wallcraft, P. J. Martin, and R. L. Pauley (2009), Optimizing surface winds using QuikSCAT measurements in the Mediterranean Sea during 2000-2006, J. Mar. Syst., 78, S119-S131, doi:10.1016/j.jmarsys. 2009.01.020.

Klein, P., B. L. Hua, G. Lappeyre, X. Capet, S. le Gentil, and H. Sasaki (2008), Upper ocean turbulence from high-resolution 3D simulations, J. Phys. Oceanogr., 38, 1748-1763, doi:10.1175/2007JPO3773.1. 
Le Traon, P. Y., P. Klein, B. L. Hua, and G. Dibarboure (2008), Do altimeter wavenumber spectra agree with the interior or surface quasigeostrophic theory?, J. Phys. Oceanogr., 38, 1137-1142, doi:10.1175/ 2007JPO3806.1.

Lévy, M., P. Klein, A.-M. Treguier, D. Iovino, G. Madec, S. Msson, and K. Takahashi (2012), Grid degradation of submesoscale resolving ocean models: Benefits for offline passive tracer transport, Ocean Modell., 48, 1-9, doi:10.1016/j.ocemod.2012.02.004.

Metzger, E. J., O. M. Smedstad, P. G. Thoppil, H. E. Hurlburt, D. S. Franklin, G. Peggion, J. F. Shriver, and A. J. Wallcraft (2010), Validation test report for the global ocean forecast system V3.0-1/12 ${ }^{\circ}$ HYCOM/NCODA: Phase II, NRL Memo. Rep. NRL/MR/7320-10-9236, Nav. Res. Lab., Stennis Space Center, Miss. [Available at http://www7320.nrlssc.navy.mil/pubs/ 2010/metzger1-2010.pdf.]

Polzin, K. L., J. M. Toole, J. R. Ledwell, and R. W. Schmitt (1997), Spatial variability of turbulent mixing in the abyssal ocean, Science, 276, 93-96, doi:10.1126/science.276.5309.93.

Ray, R. D. (1998), Ocean self-attraction and loading in numerical tidal models, Mar. Geod., 21, 181-191, doi:10.1080/01490419809388134.

Ray, R. D., and D. A. Byrne (2010), Bottom pressure tides along a line in the southern Atlantic Ocean and comparisons with satellite altimetry, Ocean Dyn., 60, 1167-1176, doi:10.1007/s10236-010-0316-0.

Ray, R. D., and G. T. Mitchum (1996), Surface manifestation of internal tides generated near Hawai'i, Geophys. Res. Lett., 23, 2101-2104, doi:10.1029/96GL02050.

Ray, R. D., and G. T. Mitchum (1997), Surface manifestation of internal tides in the deep ocean: Observations from altimetry and tide gauges, Prog. Oceanogr., 40, 135-162, doi:10.1016/S0079-6611(97)00025-6.

Ray, R. D., and E. D. Zaron (2011), Non-stationary internal tides observed with satellite altimetry, Geophys. Res. Lett., 38, L17609, doi:10.1029/ 2011 GL048617.
Rosmond, T. E., J. Teixeira, M. Peng, T. F. Hogan, and R. Pauley (2002), Navy Operational Global Atmospheric Prediction System (NOGAPS): Forcing for ocean models, Oceanography, 15, 99-108, doi:10.5670/ oceanog.2002.40

Salmon, R. (1980), Baroclinic instability and geostrophic turbulence, Geophys. Astrophys. Fluid Dyn., 15, 167-211, doi:10.1080/03091928008241178.

Sasaki, H., and P. Klein (2012), SSH wavenumber spectra in the North Pacific from a high-resolution realistic simulation, J. Phys. Oceanogr., 42, 1233-1241, doi:10.1175/JPO-D-11-0180.1.

Shriver, J. F., B. K. Arbic, J. G. Richman, R. D. Ray, E. J. Metzger, A. J. Wallcraft, and P. G. Timko (2012), An evaluation of the barotropic and internal tides in a high-resolution global ocean circulation model, J. Geophys. Res., 117, C10024, doi:10.1029/2012JC008170.

Shum, C. K., et al. (1997), Accuracy assessment of recent ocean tide models, J. Geophys. Res., 102, 25,173-25,194, doi:10.1029/97JC00445. Stammer, D. (1997), Global characteristics of ocean variability estimated from regional TOPEX/Poseidon altimeter measurements, J. Phys. Oceanogr., 27, 1743-1769, doi:10.1175/1520-0485(1997)027<1743:GCOOVE $>2.0 . C O ; 2$

Thoppil, P. G., J. G. Richman, and P. J. Hogan (2011), Energetics of a global ocean circulation model compared to observations, Geophys. Res. Lett., 38, L15607, doi:10.1029/2011GL048347.

Tierney, C. C., M. E. Parke, and G. H. Born (1998), An investigation of ocean tides derived from along-track altimetry, J. Geophys. Res., 103, 10,273-10,287, doi:10.1029/98JC00448.

$\mathrm{Xu}$, Y., and L.-L. Fu (2011), Global variability of the wavenumber spectrum of oceanic mesoscale turbulence, J. Phys. Oceanogr., 41, 802-809, doi:10.1175/2010JPO4558.1

$\mathrm{Xu}$, Y., and L.-L. Fu (2012), The effects of altimeter instrument noise on the estimation of the wavenumber spectrum of sea surface height, J. Phys. Oceanogr., doi:10.1175/JPO-D-12-0106.1, in press. 